\title{
Stuck in the Middle: Using Middle-Status Conformity to Unravel Conflicting Results in Innovation Diffusion Patterns
}

andrew.earle@unh.edu | Department of Management, Peter T. Paul College of Business \& Economics, University of New Hampshire, 10 Garrison Avenue, Durham, NH, 03824, USA

Abstract. Studies of diffusion have found conflicting patterns of inter-organizational innovation adoption. This paper uses the concept of middle-status conformity to propose a model of diffusion that helps ake sense of these conflicting results. This model is developed by combining the status-competition model (Podolny, 1993) with the audience-candidate interface model (Zuckerman, 1999). The integration of these models yields two distinct diffusion patterns characterized by status differences in originating and adopting organizations. Additionally, five empirically testable propositions are developed in order to lay the groundwork for testing this hybrid model.

Keywords. Diffusion of innovations; Technological change; Social status; New technology.

Cite paper as: Earle, A., (2018). Stuck in the Middle: Using Middle-Status Conformity to Unravel Conflicting Results in Innovation Diffusion Patterns, Journal of Innovation Management, www.open-jim.org, 6(1), 32-54. http://hdl.handle.net/10216/111571 


\section{Introduction}

Studies of innovation diffusion have often focused on whether the direction of diffusion is from low-status organizations to high-status organizations (Tripsas, 1997) or from high-status organizations to low-status organizations (Rowan, 1982; Strang and Soule, 1998; Greenwood and Suddaby, 2006). The former is consistent with high-status organizations having the most to ose from a change in the status quo, being overly focused on past successes, or rarely adopting innovations (Cooper and Schendel, 1976; Levinthal and March, 1981). In contrast, the latter pattern is consistent with the notion that the adoption of an innovation by high-status organizations provides that particular innovation a degree of legitimacy (Meyer and Rowan, 1977) and it is then adopted by lower status organizations through a process of isomorphism (DiMaggio and Powell, 1983). The labels for source and adopter groups tend to vary, for example, core and periphery (Strang and Soule, 1998) or leaders and laggards (O'Neill et al., 1998), but the essential structure of the debate remains: diffusion starts with one group and follows a roughly linear trajectory from less to more ubiquitous. The literature provides supporting evidence for both diffusion patterns, but struggles to theoretically assert which pattern we should expect in a particular case and why.

\subsection{Motivation and Research Question}

In an effort to resolve these conflicting empirical results and provide guidance to organizations trying to promote diffusion in the presence of strong status dynamics, this paper follows the advice of (Poole \& Van de Ven, 1989) and (Abrahamson, 1991) to clarify the level of analysis and more carefully consider temporal dynamics when faced with an apparent paradox. Here, this clarification takes the form of reorienting the theoretical lens for examining diffusion patterns from adoption decisions at the organization level to view such decisions as embedded in the higher-level social structure of a status hierarchy (Ravlin and Thomas, 2005).

As a result, the purpose of this paper is to focus on middle-status organizations and the unique set of behaviors with which they have been associated (Marsh and Coleman, 1956; Menzel, 1960; Blau, 1964; Becker, 1970; Zuckerman, 1999; Phillips and Zuckerman, 2001). Specifically, the behavior of middle-status organizations is far more constrained by status dynamics than the behavior of other status groups. This explicit integration of middle-status organizations into models of diffusion creates an exhaustive status hierarchy (Phillips and Zuckerman, 2001) containing low-, middle-, and high-status groups, and leads to markedly different expected patterns of innovation diffusion than the two dominant patterns identified in the literature. Thus, the central research question addressed in this study is the following: what patterns of diffusion should we expect in the context of an exhaustive status hierarchy?

We answer this research question with a novel conceptual model that both helps clarify relationships between existing studies and proposes five testable propositions for future research. The central mechanisms in our model is a hybrid of Podolny's (1993) status-based model of competition and Zuckerman's (1999) audience-candidate interface model; we label this combined model the status-audition model ${ }^{1}$. The theoretical result of integrating an exhaustive status hierarchy

${ }^{1}$ We label the model developed in this paper the "status-audition model" because it integrates the assumptions 
with the status-audition model is a three by three matrix of potential outcomes, where the three columns contain an innovation's status group origin and the three rows contain the same status groups as potential adopters. This model yields nine mathematically possible outcomes, however, only five of these outcomes are theoretically feasible in light of established dynamics of status group interactions. Furthermore, three of these outcomes - the diagonal of the matrix - simply state that organizations in the same status group can adopt innovations from one another, a result of little theoretical interest or practical importance.

This leaves two of the nine outcomes that both satisfy status constraints and represent interstatus group diffusion. The first feasible pattern is an innovation diffusing from high-status to middle-status organizations, but not to low-status organizations. The second feasible pattern is an innovation diffusing from low-status organizations to high-status organizations and then, only at a later time, to middle-status organizations. It is important to note that the status-audition model we develop in this paper predicts that high-to-low status and low-to-high status diffusion patterns (with middle-status organizations assumed to be the second adopter in both cases) will be unlikely to occur in the context of a strong status hierarchy.

\subsection{Practical Implications}

75 While our model contributes to a more nuanced and theoretically informed understanding of diffusions processes, it also provides practical guidance for those interested in promoting diffusion (e.g., policy makers, entrepreneurs with "viral" business models, etc.) For example, an entrepreneur's instinct might tell her to pitch a new idea to a middle-status organization with a value proposition of helping it catch up with leading organizations in a given field. However, since status dynamics tend to push middle-status organizations toward conformity (Phillips and Zuckerman, 2001), convincing such an organization to become an "early adopter" might prove especially difficult.

Similarly, organizations that rely on partners for diffusion, such as those in non-commercial settings including universities and national laboratories, may want to contemplate partner choice differently in light of our model. Specifically, licensing innovations to established industry partners has traditionally been the preferred mechanism for university technology transfer (Powers and McDougall, 2005), however, this may not be the most effective method to promote broad diffusion. Instead, our model predicts that licensing to relatively low-status organizations - such as startups or social ventures - would ultimately result in broader diffusion in a market charac-

90 terized by strong-status dynamics. Of course, we do not contend that organizational status is the only force at play in the process of innovation diffusion; however, we do seek to build the case that it is likely more complex, dynamic, and non-linear (Abbott, 1988) than previously assumed. To build the foundations for our model, we review selected portions of the literatures on diffusion patterns and organizational status. Then we develop the status-audition model itself. The development of this model suggests three propositions concerning diffusion patterns and two concerning the expected end state of innovation adoption once the theorized diffusion process

of loose linkages between an organization's status and its underlying product quality with the act of "auditioning" innovations for an audience consisting of high-status organizations in an effort to gain membership in the highstatus group. 
has completed multiple iterations. These five propositions complement and inform the existing literature on diffusion patterns and contribute to this literature by articulating a more complete and generalizable model of diffusion in the context of status hierarchies. This paper concludes by suggesting paths for future research, including outlining the ideal setting for an empirical test of the status-audition model.

\section{Related Work}

A review of the complete body of work on innovation diffusion and organizational status is outside of the scope of this study, but there are specific areas of these literatures that highlight the conflict this study seeks to address. First, we review literature on innovation diffusion patterns. It is important to note that the pattern itself, rather than the mechanism or channel of diffusion, is what we focus on in this study. The main goal of reviewing this portion of the literature is to demonstrate that low-to-high status (periphery to core) and high-to-low status (core to periphery) are common directional findings in studies of diffusion patterns. The secondary goal is to show that these status and positional concepts are closely related and sometimes used interchangeably by scholars; examples include studies by (Ibarra, 1993) and (Rowley, 1997). The second vein of literature we review is on organizational status with a particular focus on statusbased competition and middle-status conformity. Combining insights from these literatures leads us to integrate middle-status conformity into status-based models of competition to form the core contribution of this paper.

\subsection{Innovation and Diffusion}

Diffusion is a highly generalized social process critical to social analysis (Strang and Meyer, 1993) that scholars have studied in many empirical settings. In the words of Strang and Meyer (1993, p. 487), "Virtually everything seems to diffuse: rumors, prescription practices, boiled drinking water, totems, hybrid corn, job classification systems, organizational structures, church attendance, national sovereignty." For the purpose of this study, we keep both diffusion and innovation at a fairly high level of abstraction. This is consistent with Rogers' definition of diffusion: when "an innovation is communicated through certain channels over time among the members of a social system." (1995, pg. 5) In this context, innovation is also defined abstractly as being synonymous with a practice and taking a wide variety of forms including structures, policies, attitudes, etc. (Strang and Meyer, 1993) While this level of abstraction may pose theoretical difficulties for certain research questions, it fits the central question of this study nicely in that it is not tied to a certain type of innovation, mechanism, channel, or setting.

This literature has investigated a number of fruitful aspects of diffusion including diffusion rates (Strang and Soule, 1998), patterns (Greve, 1996), mechanisms of transference (Burt, 1987; Ahuja, 2000), and adoption intensity (Abrahamson and Rosenkopf, 1993). Studies of status and diffusion tend to either examine the directionality within a status dyad (for example, Greenwood and Suddaby's (2006) use of the "big five" and "other" accounting firms) or remain agnostic to the role of status groups and simply assess overall adoption frequency as a measure of a particular innovation's status (Tolbert and Zucker, 1983). 
With empirical evidence for both patterns of directionality, this topic risks being tossed on to the "both, and" scrap heap of seemingly un-resolvable paradoxes. Fortunately, a more nuanced treatment of organizational status and status hierarchies can help resolve the apparent contradictions of these studies by providing a theoretical foundation for why documented patterns of diffusion differ so radically.

\subsection{Organizational Status}

The fundamental goal of this study is to better integrate the insights from the literature on status hierarchies into the study of diffusion patterns. As a result, we limit our literature review to defining status hierarchies, reviewing Podolny's model of status based competition (Podolny. 1993), outlining findings on middle-status conformity, and describing (Zuckerman, 1999) candidate-audience interface model.

Research on organizational status and its competitive consequences is anchored in the institutional branch of organizational sociology with many studies (e.g., Meyer and Rowan, 1977; DiMaggio and Powell, 1983) in this area proving highly influential in the field of management as well (Suchman, 1995). As such, differences in organizational status and their associated dynamics may be as much a result of "myths and ceremonies" and concerns over perceived legitimacy as technological or economic efficacy (Meyer and Rowan, 1977). More specifically, organizational status is a specialized application of stratification theory, which theorizes a distinction between actors and actors' positions in a social structure (Podolny, 1993). In this study, the "actor" is an organization and the "social structure" of interest is a status hierarchy. (White, 1981) introduced the notion that organizations in a market context occupy socially constructed positions relative to other organizations engaged in similar productive activities. Since the level of analysis here is an industry, market, or other competing set of organizations, status hierarchy is the appropriate status construct to employ as opposed to "status" or "stratification" which apply to individuals or societies, respectively (Ravlin and Thomas, 2005).

(Ridgeway \& Walker 1995) define status structures (including hierarchies) as "patterned inequalities of respect, deference, and influence among a group." The consequence of this definition is that status hierarchies are relational and exist only at the aggregate level (Ravlin and Thomas, 2005). Furthermore, status hierarchies can be thought of as an index measure of underlying competency where ordinal comparisons are far easier to make than cardinal ones. In a similar vein, status hierarchies have been described as summary mechanisms (Ravlin and Thomas, 2005) that are loosely linked to underlying quality (Podolny, 1993).

We frame the central argument in this study in terms of relative position within a status hierarchy. As result, we treat other positional terminology, such as core and periphery, as interchangeable with their status-based equivalents: high- and low- status positions. This is consistent with research that employs these terms interchangeably (Meyer and Rowan, 1977). The choice of status-based terminology over structural position-based terminology is essentially arbitrary, as recasting the status-audition models in terms of structural position terminology would not alter the predictions of the model. 
ISSN 2183-0606

http://www.open-jim.org

http://creativecommons.org/licenses/by/3.0

\subsection{Status-Based Competition} (Podolny, 1993).

\subsection{Middle-Status Organizations}

Perhaps the most precise enumeration of competition in the context of a status hierarchy is Podolny's "A Status Based Model of Market Competition" (Podolny, 1993). It examines how an organization's status position in a market affects its opportunities relative to its competitor organizations. Here, he defines status as "the perceived quality of that producer's products in relation to the perceived quality of that producer's competition" (p. 830). While status can be an end unto itself as observed by (Frank, 1985), Podolny argues that status' role as a signal of underlying and unobservable product quality is the central mechanism by which status hierarchies are created. This occurs in a situation when the quality of a good is impossible or expensive to assess in a meaningful way prior to a transaction, so the status of the producing organization is used as a proxy measure of quality. The result is that actual product quality and status are only loosely linked with tighter linkages foiled by time lags, the stochastic nature of the link, producer's relationships with others in the market, and difficultly of measurement

Considering status as an imperfect proxy for underlying quality and that organizations can be meaningfully ranked by this single dimension (including summary dimensions such as reputation, prestige, etc.), along with the assumption of bounded rationality (Simon, 1957), creates the theoretical conditions for the existence of status hierarchies. The status-based model of competition seeks to occupy a middle-ground between economics-oriented models that assume perfect linkages between actors and positions - in which status would be a meaningless concept - and sociological models which have been criticized as overly socialized (Granovetter, 1992). In other words, the former assumes perfect actor-position linkages, while the latter assumes no actorposition linkages whatsoever. This approach is consistent with Granovetter's (1992) warning regarding under- or over-socializing models of organizational phenomena.

Empirical evidence in support of the status-based model of competition is offered by (Podolny, 1993) in the setting of investment banking. Here he demonstrates that after controlling for such relevant variables as volume of transactions, position in the status hierarchy still maintains a large and significant effect on investment banks' bidding abilities. Furthermore, he demonstrates that even large changes in instrumental measures such as deal volume "do not overwhelm even small differences in the status order" (p. 863). Other studies have found similar effects in a diverse range of industries including law and financial analysis (Phillips and Zuckerman, 2001).

The notion that conformity is lower as an organization moves in either direction on a status continuum from the midpoint is not a new concept (Marsh and Coleman, 1956; Menzel, 1960, Blau, 1964; Becker, 1970; Zuckerman, 1999; Philips and Zuckerman, 2001). However, researchers have not integrated it with the study of status-based competition or diffusion. The classic presentation of this phenomenon is an inverted " $U$ " shape with conformity on the vertical axis and status on the horizontal axis. The interpretation of this shape offered by Phillips and Zuckerman (2001) is that high-status actors, sufficiently secure in the hierarchy, can deviate from conventional behavior (i.e., innovate) without risking their position. Furthermore, lowstatus actors are excluded from the benefits of the hierarchy, a priori, and so are also free to be 
deviant since their chance of ascension in the hierarchy is essentially zero. The case of middlestatus actors is peculiar in that they "have membership in a group, but feel insecure in that membership" (Dittes and Kelley, 1956).

At first, the notion of three distinct status groups may seem no less arbitrary than two status groups (i.e., "low" and "high"); however, the use of three status groups is not an arbitrary division. Rather, they stem from the three possible positions an actor can have relative to a boundary: one side, straddling, or the other side (Phillips and Zuckerman, 2001). In a status hierarchy, an actor is in one of three positions: unquestionably legitimate (high-status), unquestionably illegitimate (low-status), or as a candidate for legitimacy (middle-status). While the first two groups are largely free from pressure to conform, the third group is under careful scrutiny by higher-status actors and relevant external audiences (Phillips and Zuckerman, 2001). These three categories of groups therefore form an exhaustive status hierarchy, which is necessary for understanding diffusion patterns in their entirety.

Empirical studies of the inverted "U" pattern of status and conformity in terms of innovation diffusion have yielded a mixed result with Phillips and Zuckerman (2001) pointing to studies that both find evidence for this pattern (Marsh and Coleman, 1956; Blau, 1960; Menzel, 1960; Becker, 1970) and studies that do not find support for it (Cancian, 1967; Gartell, 1977). These conflicting results were never resolved and the relevant research traditions moved on to study other phenomena (Phillips and Zuckerman, 2001).

\subsection{Candidate-Audience Interface}

In the model we develop in this paper, the counterpart to the status-competition model introduced above is the candidate-audience interface model developed by Zuckerman (1999). The basic premise of this model includes an audience that first ranks "candidates." This rank interacts with the candidate's actual performance to determine the audience's evaluation of the candidate. For the purposes of this study, the audience is composed of high-status organizations and possibly consequential outside entities such as regulators, media outlets, funding sources, rating agencies, etc.

An example of a candidate-audience interface would be the application process for Ph.D. programs. Here the candidate for admission must present the audience (consisting of the graduate school and the admissions committee) with a case for their admission consisting of numerous elements, some with tight linkages between quality and status such as test scores, and others with looser linkages such as grade point average from a particular institution. Some applicants may be accepted or rejected automatically based their educational history (including status elements), regardless of the how well their case is presented (for example, the quality of written admission essays). It would be the marginally "admitable" (i.e., middle-status) candidate who would fall under the greatest pressure to conform to the audience's expectations. The audience's ultimate evaluation is driven partly by status and partly by presentation quality. This makes the candidate-audience interface model complementary to the lose linkages central to the status-based model of competition introduced earlier.

Phillips and Zuckerman (2001) tested this model which provided strong evidence for middlestatus conformity in the context of status hierarchies using the organization as the unit of analysis. 
Specifically, they tested it with both Silicon Valley law firms' propensity to adopt family law practices (a low-status innovation) and analysts' propensity to issue "sell" recommendation - an action that would undoubtedly anger audience members. In both cases the researchers observed a clearly defined inverted "U" pattern, a finding consistent with theory on middle-status conformity.

\section{The Status-Audition Model}

This literature review illustrates the need for a model of innovation diffusion in the context of status hierarchies that both theoretically integrates middle-status conformity, and helps to unravel the seemingly contradictory diffusion patterns observed in previous studies. The statusaudition model we develop here draws on both the status-based competition model developed by (Podolny, 1993) and the candidate-audience interface model developed by Zuckerman (1999). The major difference in our model is that organizations are not auditioning to move up the status hierarchy per se, but are auditioning innovations to be viewed as legitimate by higherstatus organizations as well as internal and external stakeholders (collectively referred to as the "audience") (Freeman, 2010). While this distinction is subtle, it allows innovations to diffuse rapidly in a stable status hierarchy, rather than requiring a reordering of the status hierarchy itself. This is important because status hierarchies have been shown to be remarkably stable over time (Podolny, 1993; Stewart, 2005), so a viable model must offer a mechanism for innovation diffusion that does not rely on the constant reordering of the status hierarchy to drive the process.

The status-audition model treats diffusion as a function of the status group origin of an innovation as well as the status of past adopters (we label this an innovation's "provenance") and time. This implies three distinct paths of diffusion, one each for innovations originating in low-, middle-, and high-status group organizations with the status of an innovation's adopter being revaluated at the end of each time period. These patterns differ radically because the status-audition model process places differing demands on organizations in each status group. In other words, organizations in a given status group are limited in which other status groups they can adopt innovations from and still be seen as legitimate status group members by the relevant audience. It is this status-constrained process of adoption, under the watchful eye of the audience, that produces the proposed patterns of diffusion.

Figure 1 shows the generalized status-audition model, however, it is important to note that the options available to organizations will vary at each step based on their position in the status hierarchy. The first step is consistent with the status-competition model (Podolny, 1993) in which organizations are aware of innovations originating in, and adopted by, other members of status groups. In the second step, the innovation's provenance is established and then considered in light of the audiences' expected reaction. The third step is consistent with the candidate-audience interface model as an organization weighs the cost and benefits of auditioning the innovation for the audience. 


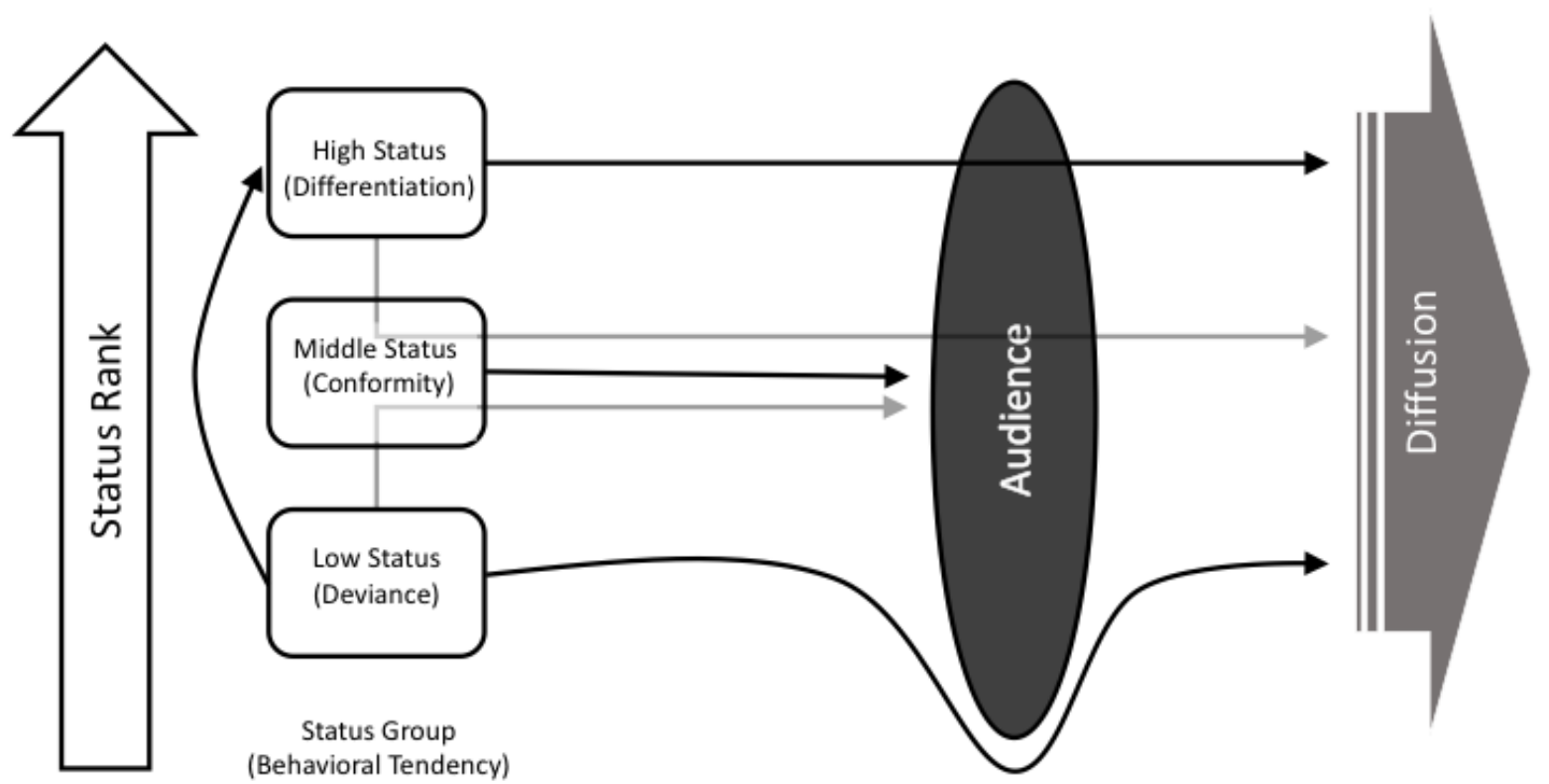

Fig. 1. Status-Audition Model (Partially Based on Phillips and Zuckerman's CandidateAudience Interface model (2001))

The status-audition model is not primarily concerned with the actual reason for adoption of an innovation as this issue has been thoroughly investigated and convincingly shown to be a blend of instrumental and symbolic reasons with the relative proportion tending to move from more instrumental to more symbolic over time (Tolbert and Zucker, 1983; Westphal and Zajack, 1994). Instead, our goal is to explain the likelihood of inter-organizational adoption of innovations when these organizations are asymmetric in status. This goal implies some logical boundary conditions for the predictions of this model to focus in on what it tries to explain and what it does not. First, its predictions will be most likely observed in highly institutionalized settings where status matters a great deal in decision making (e.g., universities) (Burris, 2004). Second, since the innovation adoption process is complex, with status being one of many factors considered in adoption decisions, all propositions should be considered as if all other factors are equal. Third, we assume innovations in this context are observable by potential adopter organizations (i.e., not cases of "concealed adoption") (Terlaak and Gong, 2008), and have the potential to be adopted in the sense that some portion of the innovation can be mimicked by the adopting organization.

This model is constant with studies on environmental scanning where organizations are consistently looking for innovations (Miller and Friesen, 1982; Van de Ven, 1986; Khan and Manopichetwattana, 1989), regardless of whether they are symbolic or instrumental in value. This implies that organizations devoting at least some resources, formally or informally, to searching for useful innovations will be at least partially aware of the innovations adopted by organizations in other status groups. The status-audition model does not rely on the assumptions that organizations can perfectly assess all innovations adopted by other organizations or determine the future value 
of a given innovation cost free; instead, it merely requires an imperfect knowledge of innovation adoption by organizations in other status groups. Furthermore, this model is only concerned with when an innovation is actually adopted by a given organization, implying that the "boundedly" rational (Simon, 1957) managers of that organization must have believed that such an adoption would prove beneficial to the organization.

With the assumptions and boundary conditions of the status-audition model clearly stated, it is now important to be explicit in regard to its mechanisms and directionality. The innovation adoption process begins when an organization scans its environment - which mostly consists of other organizations (Hannan and Freeman, 1977) - in an effort to identify useful innovations. The organization limits its scanning process to status groups that can produce innovations that the relevant audience views as legitimate in order to protect - and potentially improve - its position in the status hierarchy. At the heart of this model is the notion that the provenance of an innovation matters according to which status groups will choose to adopt it.

\subsection{Status and Diffusion}

In terms of the status-audition model, low-status organizations are those that the audience does not consider to be serious candidates for hierarchy ascension. As a result, those organizations have a strong incentive to refrain from participating in status auditions. This is because conformity, in the form of adopting innovations prevalent in middle- or high-status organizations, is not enough to change low-status organizations' positions in the status hierarchy. In other words, the audience dismisses low-status organizations a priori so the audition of an innovation would tend not to occur. As a result, we predict low-status organization will either develop innovations internally or adopt innovations from other low-status organizations.

Proposition 1. In the context of a status hierarchy, low-status organizations tend not to adopt inter-status group innovations.

The status-audition model makes the prediction that a high-to-low status diffusion pattern would be unlikely to occur within the boundaries outlined in this paper. While this is a bold claim, such a mirage can be generated by either utilizing an incomplete status hierarchy for source data - therefore mistaking middle-status organizations for low-status organizations - or by combining middle- and low-status organizations into a single group in which the characteristics of the former dominate. In the first case, the lack of a true low-status group (i.e., a true periphery) creates what would appear to be diffusion across the entire status hierarchy, but in fact would be showing a truncated diffusion process. In the second case, mixing of middle-status and low-status groups yields a top to bottom diffusion pattern in a status hierarchy, but this is simply due to the influence of the middle-status cases (as opposed to the low-status cases) in a data set partitioned into high-status group organizations and "others." Combining middle- and low-status group organizations would be acceptable only if low-status organizations were simply more extreme cases of middle-status organizations, a fact not supported by research in this area (e.g., Phillips and Zuckerman, 2001). Figures 2a and 2b provide a graphical representation of each scenario. 


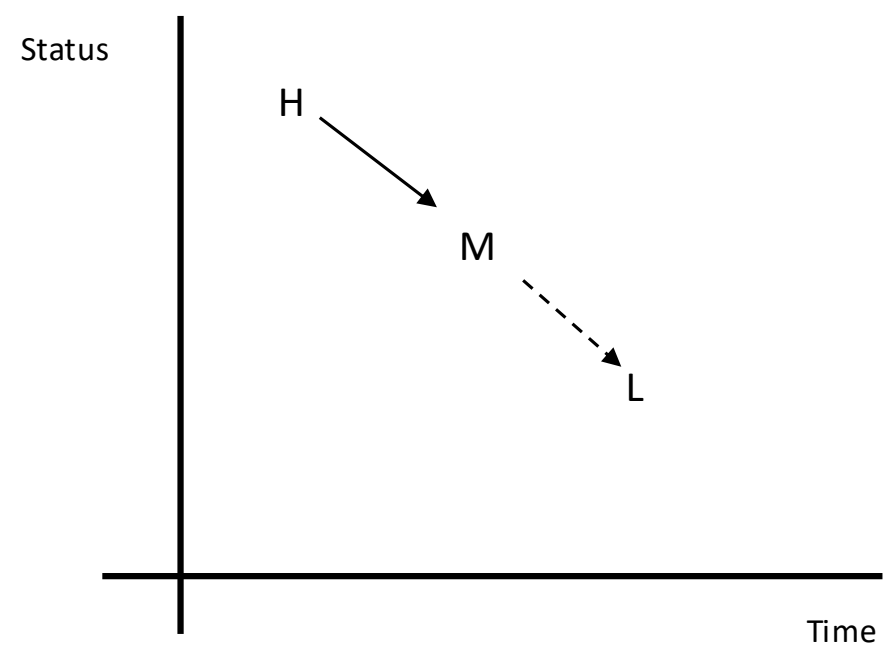

Fig. 2a. Diffusion in an Incomplete Status Hierarchy

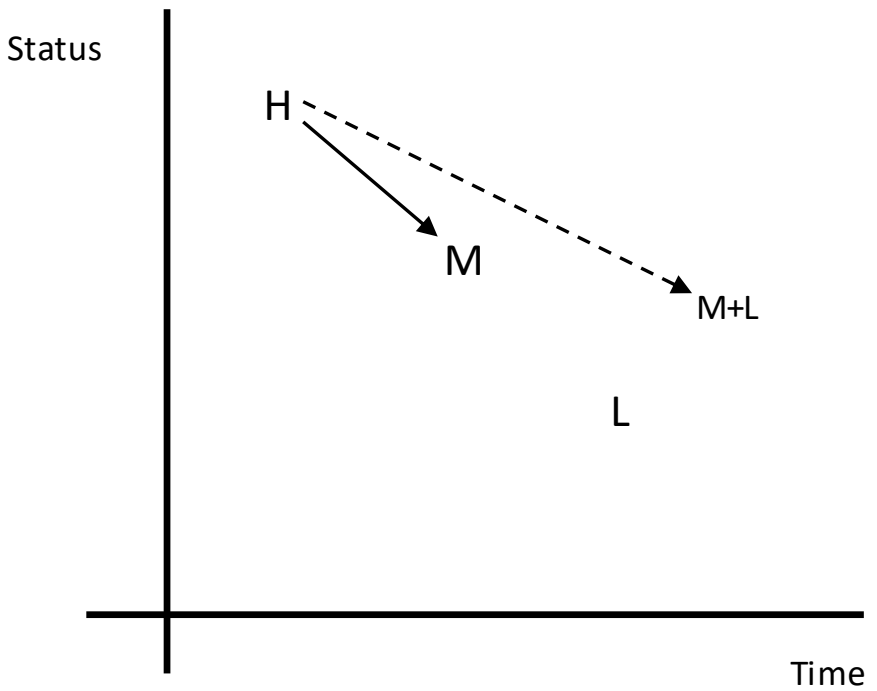

Fig. 2b. Diffusion in a Compound Status Hierarchy

Middle-status organizations are central to the status-audition model, as they tend to adopt innovations with high-status provenance in order to secure their place in the status hierarchy. Such an arrangement lessens the chance of diffusion from low-status organizations to middlestatus organizations. This leaves only one potential inter-status group source for innovations for middle-status organizations: high status organizations. This is classic middle-status conformity in an organizational setting:

Proposition 2. In the context of a status hierarchy, middle-status organizations tend to adopt inter-status group innovations of high-status provenance. 
It is important to note that middle-status organizations' attempts to ascend the status hierarchy are consistent with status hierarchies being predominantly stable. First, the adoption of any single innovation is unlikely to fundamentally alter the status of an organization simply because organizations are complex (Simon, 1973). The accretion of successful innovations over extended periods of time may influence positions in the status hierarchy, but this tends to be a long process that would not result in dramatic shifts in status group membership over short-time horizons (Podolny, 1993).

Second, the adoption of high-status innovations by middle-status organizations is based on the expectation that it will improve an organization's status and permit ascension of the status hierarchy. Whether or not this actually occurs is immaterial since each innovation is largely unique and its adoption's impact on organizational performance is difficult, if not impossible, to determine with any degree of certainty a priori (Orlikowski, 1996).

The theoretical ramifications of these challenges to mobility reinforce the status hierarchy because middle-status organizations tend to adopt innovations that have already been adopted by highstatus organizations, thereby foiling attempts to move up the status hierarchy with the adoption of an especially effective "disruptive" type of innovation. Therefore, an implication of a strongstatus hierarchy is that the auditioning process essentially becomes a trap for middle-status organizations. By the time they become aware of the adoption of an innovation by high-status group organizations and attempt to adopt it themselves, the innovation is - by definition - no longer rare or inimitable and therefore problematic as a source of competitive advantage (Barney, 1991; Denrell, 2005). This result also holds for innovations that are symbolic in nature as long as being innovative is a distinguishing feature of the high-status group because mimicry does not in itself produce performance (Levinthal and March, 1981).

In the status-audition model, high-status group organizations are truly legitimate in the Meyer and Rowan (1977) sense, in that what innovations they choose to adopt go unquestioned. Theoretically, this legitimacy gives high-status group organizations carte blanche over all three status groups as sources for innovations to adopt; however, since middle-status organizations are essentially filled with innovations that originated in the high-status group to begin with, the only viable inter-status group source for novel innovations is the low-status group.

Proposition 3. In the context of a status hierarchy, high-status group organizations tend to adopt inter-status group innovations of low-status provenance.

The three propositions generated from the status-audition model provide theoretical support for stability in status hierarchies. Low-status organization are free to innovate but are disregarded as serious candidates for the ascension of the status hierarchy. Middle-status organization must adopt innovations already utilized by high-status group organizations or they risk audience disapproval and imperil their position in the hierarchy. High-status organizations are free to innovate and will be mimicked by middle-status group organizations regardless of the provenance of the innovation they choose to adopt. While this model predicts stability in status hierarchies, it does not argue that status hierarchies are stagnant.

Movement can occur over time as certain organizations either fail or excel at their respective roles in their respective status groups (Podolny, 1993). For example, if a high-status organization 
continually adopts innovations that turn out to have little or no instrumental or symbolic value, or adopts too many innovations from low-status organizations, its status position may begin to erode. On the other end of the spectrum, if a low-status organization is repeatedly the source of valuable innovations for high-status organizations, it may become a more carefully considered candidate for promotion in the status hierarchy.

\subsection{Status Groups and Diffusion Over Time}

In considering the status-audition model over time, we focus on a situation where the legitimacy of an innovation (from the perspective of the relevant audience) is the driving force in its adoption. We use this extreme case to foreground the role of status hierarchies in diffusion. However, in accordance with much of the institutional-focused research on organizations, we acknowledge that such decisions are complex and often include a mix of institutional pressures and effectivenessbased considerations (Westphal et al., 1997). As a result, the diffusion matrices we develop in figures $3 \mathrm{a}$ and $3 \mathrm{~b}$ can be interpreted as "all else equal" when institutional pressures (in the form of status dynamics) are the dominant consideration in a given adoption decision.

If the provenance of an innovation was perfectly linked to its efficacy (pure efficiency), the statusaudition model implies nine options for diffusion (as an innovation could move from one status group to any of the others based on perfectly unbiased assessment of its costs and benefits.) On the other end of the spectrum, if there were no linkage between an innovation's efficacy and provenance (pure status), diffusion would take place only from the top of the hierarchy to the bottom. However, in the in-between case where efficacy and provenance both matter (as we assume in the status-audition model), the number of possible diffusion patterns lies between the two extremes.

Starting with the nine-cell matrix and winnowing down the options using the status-audition model eliminates cells $\mathrm{C}, \mathrm{D}, \mathrm{F}$, and $\mathrm{H}$. We climate cells $\mathrm{C}$ and $\mathrm{F}$ because low-status group organizations do not benefit from auditioning their innovations for higher-status group audiences. We eliminate D because innovations in middle-status organizations have high-status group origins (from previous iterations of diffusion). Furthermore, we eliminate $\mathrm{H}$ because the adoption of an innovation of low-status provenance would endanger the position of a middle-status organization when auditioned for a high-status group audience.

Cells A, E, and I are perfectly valid diffusion patterns, but are of little theoretical interest here because they simply show that innovations can diffuse within status groups in the context of a status hierarchy. Such intra-status group diffusion may very well be how the majority of diffusion takes place, but theorizing and discussing such dynamics are outside of the scope of this paper.

This leaves cells B and $\mathrm{G}$ as the diffusion patterns of primary interest. The cell B pattern is for an innovation to diffuse from high-status group organizations to middle-status group organizations. Initially this appears to be a classic story of core-to-periphery diffusion as an innovation works its ways down the hierarchy. However, the innovation will tend not be adopted by low-status organizations since, despite the provenance of the innovation, the organization's status will prevent it from being successful in status auditions regardless of the efficacy of the innovation. In other words, low-status organizations will refuse to enter a contest they cannot win no matter the quality of the innovation they audition. This blunts the diffusion process at the middle-status 
455

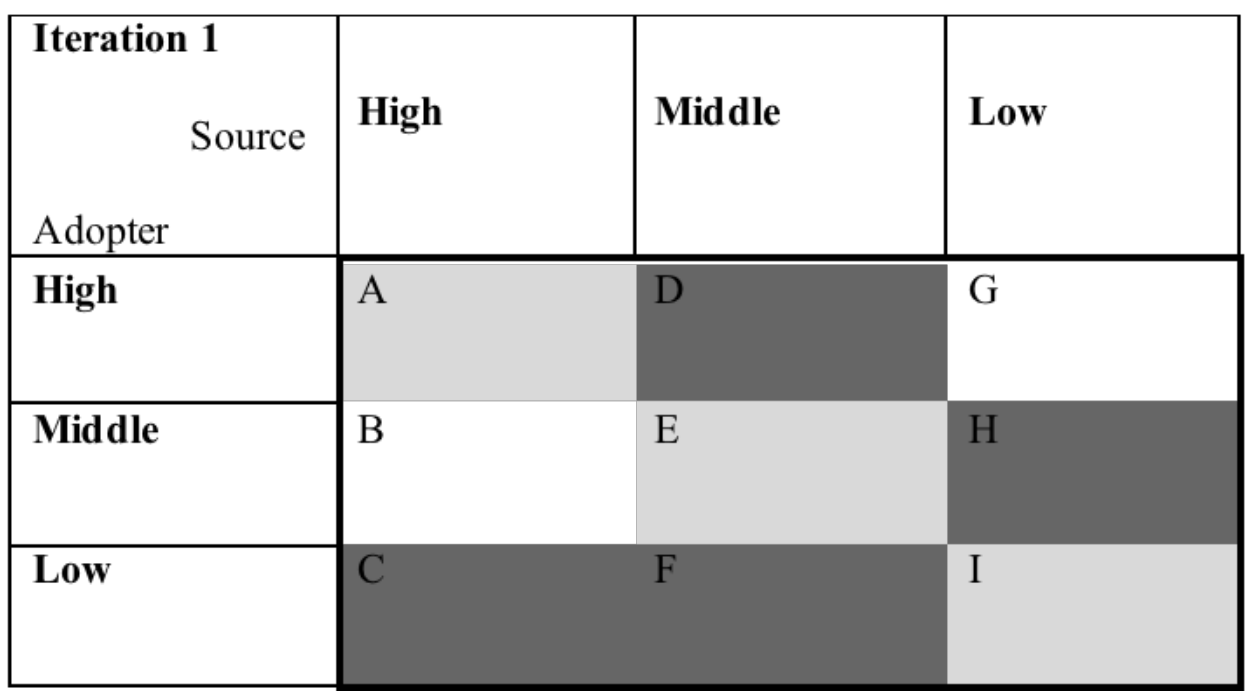

Fig. 3a. Iteration 1 Diffusion Matrix

475

At this point, it would appear that no innovation could diffuse across the entire hierarchy, but this observation would be inaccurate. This model treats diffusion explicitly as a function of provenance and time. So, while the cell B pattern would stagnate after the first iteration of the process, the cell $\mathrm{G}$ pattern would continue through a second iteration. Theoretically, this continwould lead to the adoption of the innovation of low-status provenance by middle-status organizations because high-status organization had already adopted it in the previous iteration. Therefore, cell $\mathrm{H}$ would become an end state possibility resulting in the entirety of the low-status provenance column being feasible outcomes. Figure 3b graphically illustrates this end state after

ISSN 2183-0606

http://www.open-jim.org

http://creativecommons.org/licenses/by/3.0 
two rounds of diffusion.

485

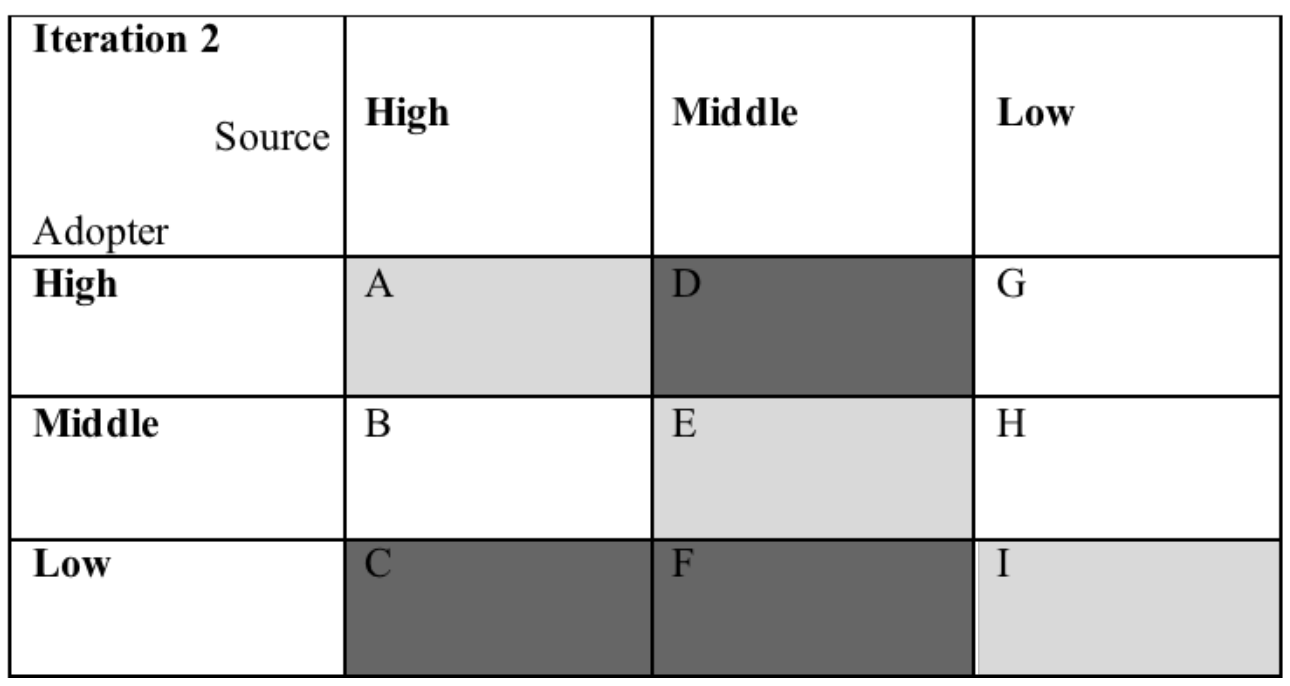

Fig. 3b. Iteration 2 Diffusion Matrix

While the status-audition model provides insight into innovation diffusion patterns, it also implies two distinct possibilities for the end state of an innovation once the diffusion process has occurred. The pattern created when an innovation originates in the high-status group leads to an end state where an innovation would tend to not fully diffuse in the status hierarchy, and, as such, can be expected to appear disproportionately in high- and middle-status organizations. This contrasts with the end state expected when an innovation has low-status origins, where our model predicts it will be found throughout the entire status hierarchy after some length of time. These expected end states generate propositions 4 and 5 .

Proposition 4. Innovations of high-or medium-status provenance tend not be found in low-status organizations (Figure 4a).

Proposition 5. Innovations of low-status provenance tend to be found throughout the entire status hierarchy after some period of time (Figure 4b).

The theoretical implication of these propositions is the counterintuitive prediction that innovations of low-status provenance should have a larger impact than innovations of high-status provenance in terms of breadth of diffusion. 
Journal of Innovation Management

Earle JIM 6, 1 (2018) 32-54

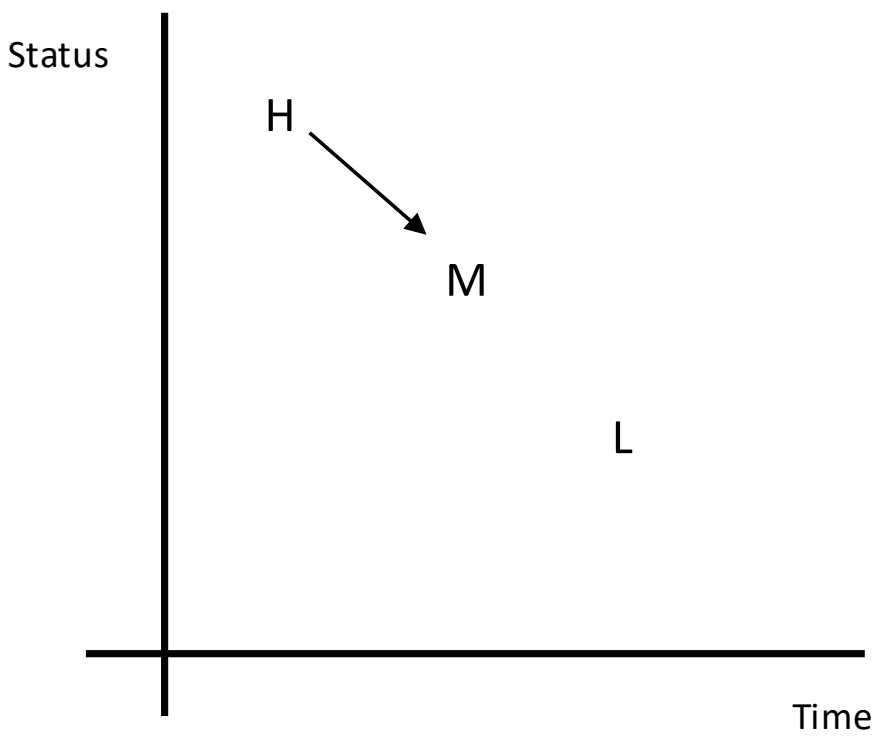

505

Fig. 4a. High Status Provenance Diffusion Pattern

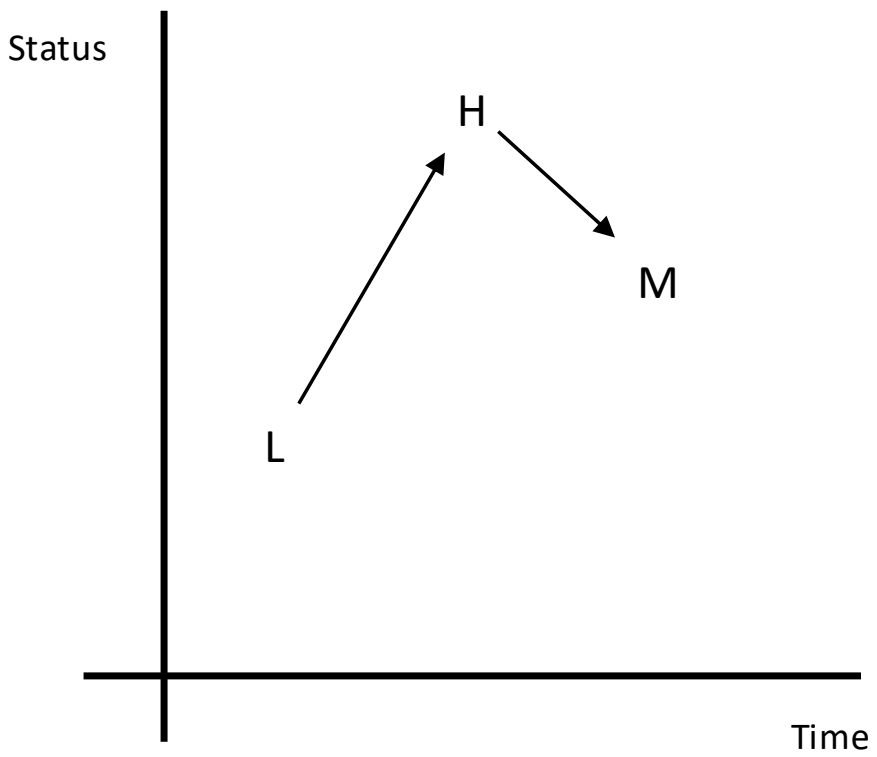

Fig. 4b. Low Status Provenance Diffusion Pattern

\section{Discussion}

The main contribution of this paper is to the development of the status-audition model, which helps resolve the conflicting empirical evidence on diffusion patterns. By raising the level of analysis to the status hierarchy and integrating the candidate-audience interface model with 
the model of status-based competition to create the status-audition model, this paper blends sociologic and economic mechanisms, along with an explicit consideration of time, to shed light on a possible explanation for the conflicting patterns of diffusion observed in past studies. As a result, this model helps free innovation diffusion research from the task of simply amassing more evidence for one side or the other of the low-to-high or high-to-low debate by providing a theoretical foundation for what type of diffusion pattern we can expect based on two readily observable variables: (i) an innovation's provenance, and (ii) the time since its initial adoption. This study also contributes to the literature by demonstrating that an exhaustive status hierarchy is necessary to ensure we observe complete diffusion processes. Alternatively, if we use an incomplete hierarchy to map diffusion, and its directionality is simply extrapolated to missing status groups, our analysis risks errant conclusions. Finally, this study calls into question the completeness of past studies that have ignored middle-status organizations and the unique behaviors associated with them. The implication of the model developed here is that low-to-high versus high-to-low is a possibly misguided debate, although empirical testing of the status-audition model (preferably using data from past studies) is needed to determine whether this model does indeed represent an improvement over existing models.

\subsection{Future Research}

The next step for future research is to empirically test the status-audition model proposed and developed in this study. The ideal setting for such a test would have three defining features: first, it would be a status hierarchy with organizations of low-, middle-, and high-statuses. Ideally, this hierarchy would encompass an entire population of organizations in a given empirical setting, but at a minimum, it should be a representative sample of a relevant population. Second, this population of organizations would exhibit clear and widely recognized status rankings among members. Finally, this setting would need to have a reliable way for an outside observer to track the diffusion of innovations as strategic avoidance, symbolic adoption, and similar dynamics can make true diffusion difficult to detect, which in turn can cause systemic errors in its assessment using common measurement approaches (Nelson et al., 2014).

Examples of sites that would be appropriate for such empirical tests include professional services firms, creative services firms, universities, and other settings were status and output quality are loosely linked. As a concrete example of how the status-audition model could be applied and tested in future research, we could consider the ubiquitous rankings of business schools published by U.S. News and World Report, the Financial Times, and similar outlets as an empirical setting. In this context, we could then look for an innovation and track its diffusion throughout a status hierarchy. For example, we could examine on-campus "makerspaces" (places where students can freely access tools and materials to build things unrelated to specific classes), an innovation which originated in the most elite science and engineering universities such as MIT and Stanford. In this setting, the adoption of such innovations are often widely publicized in marketing efforts for academic programs, and would therefore be observable on a large scale to researchers. Our model predicts an innovation like these makerspaces, given its high-status provenance, would diffuse to middle-status universities (e.g., state research universities trying to imitate MIT or Stanford), but not to low-status universities (e.g., universities with mostly part-time students who are not 
trying to imitate these high-status organizations).

In a similar vein, researchers could examine innovations with low-status provenance, such as online courses, to see if they diffuse in a linear manner (i.e., low- to middle- to high-status universities) or if they tend to follow the non-linear path suggested by our model (i.e., low- to high- to middle-status universities). As with the example of the maker spaces, the availability (and prevalence) of online classes in a given program could be observed on a fairly large scale by researchers and thus used to test one of the core predictions of our model.

\subsection{Managerial Implications}

The main managerial implications of our model derive from diffusion being an important performance indicator for many organizations and a strategic goal, in its own right, for many others. Although such diffusion has long been an objective of many organizations, the advent of viral business models, the accelerated pace of technological change, and the more general movement away from "linear reality" in management theory (Abbott, 1988; Van de Ven \& Poole, 2005), have all helped rekindle interest in the dynamics of how innovations diffuse. For example, universities are more engaged than ever before in efforts to diffuse science-based solutions to pressing problems such as climate change (Trencher et al., 2013), and "institutional entrepreneurs" are engaging in concerted efforts to broadly diffuse changes in public policy (e.g., Maguire et al., 2004). So no matter what the underlying innovation or the driving force behind an organization's desire to diffuse it, a more nuanced and informed view of diffusion processes will be useful to managers facing increasingly accelerated, complex, and non-linear environments.

Beyond a more nuanced understanding of how to promote the diffusion of a particular innovation in pursuit of organizational goals, our model also offers guidance that aligns with some seemingly counterintuitive moves made by organizations in industries with strong-status dynamics. Returning to the example of higher education, a number of good-but-not-best universities have declined to participate in the influential ranking schemes mentioned earlier (Finder, 2007).

Given the visibility of these rankings, it might seem strange that organizations would forgo such "free" advertising; however, when viewed from the perspective of the status-audition model, such moves make more strategic sense. In a strict status hierarchy, a middle-status organization is trapped by its only source of legitimate innovation which stems from those organizations above it in the hierarchy. As such, these organizations will continue to struggle to do anything that is both unique and legitimate from the perspective of their traditional "audiences." Consequentially, in refusing to participate (i.e., refusing to "audition") by dropping out of the rankings process, it would allow such universities to either develop a new status hierarchy of their own design or attempt to signal value directly to potential students through other means, such as promoting holistic and experiential education instead of foregrounding faculty with illustrious publication records (often a main driver of traditional rankings schemes) (Finder, 2007). Essentially, leaders of these universities have realized such ranking schemes are a game that middle-status organizations cannot win and have necessarily refocused their effort on alterative innovations, audiences, or both. 


\subsection{Conclusion}

Merging models of status-based competition with the candidate-audience interface to analyze diffusion patterns leads to a more thorough understanding of diffusion processes. The statusaudition model developed in this study uses middle-status conformity to expand on previously identified patterns of innovation diffusion on the basis of completeness within a status hierarchy. This results in the generation of five empirically testable propositions and two unique diffusion patterns. If supported empirically, this new model of diffusion would have consequences for management scholars as well as policy makers and management practitioners.

\section{References}

Abbott, A. (1988). Transcending general linear reality. Sociological Theory, 169-186.

Abrahamson, E. (1991). Managerial fads and fashions: The diffusion and rejection of innovations. Academy of Management Review, 16(3), 586-612.

Abrahamson, E., \& Rosenkopf, L. (1993). Institutional and competitive bandwagons: Using mathematical modeling as a tool to explore innovation diffusion. Academy of Management Review, $18(3), 487-517$.

- Ahuja, G. (2000). Collaboration networks, structural holes, and innovation: A longitudinal study. Administrative Science Quarterly, 45(3), 425-455.

Barney, J. (1991). Firm resources and sustained competitive advantage. Journal of Management, 17(1), 99-120.

Becker, M. H. (1970). Sociometric location and innovativeness: Reformulation and extension of the diffusion model. American Sociological Review, 267-282.

Blau, P. M. (1960). Patterns of deviation in work groups. Sociometry, 23(3), 245-261.

Blau, P. M. (1964). Exchange and power in social life. New York: John Wiley.

Burris, V. (2004). The academic caste system: Prestige hierarchies in PhD exchange networks. American Sociological Review, 69(2), 239-264.

Burt, R. S. (1987). Social contagion and innovation: Cohesion versus structural equivalence. American Journal of Sociology, 92(6), 1287-1335.

Cancian, F. (1967). Stratification and risk-taking: A theory tested on agricultural innovation. American Sociological Review, 912-927.

Cooper, A. C., \& Schendel, D. (1976). Strategic responses to technological threats. Business Horizons, 19(1), 61-69.

Denrell, J. (2005). Should we be impressed with high performance? Journal of Management Inquiry, 14 (3), 292-298.

DiMaggio, P., \& Powell, W. W. (1983). The iron cage revisited: Collective rationality and institutional isomorphism in organizational fields. American Sociological Review, 48(2), 147-160. 
Dittes, J. E., \& Kelley, H. H. (1956). Effects of different conditions of acceptance upon conformity to group norms. The Journal of Abnormal and Social Psychology, 53(1), 100.

Frank, R. H. (1985). Choosing the right pond: Human behavior and the quest for status. Oxford University Press.

Freeman, R. E. (2010). Strategic management: A stakeholder approach. New York: Cambridge University Press.

Finder, A. (2007, June). Some colleges to drop out of U.S. news rankings. New York Times, p. 20 .

Gartrell, J. W. (1977). Status, inequality and innovation: The green revolution in Andra Pradesh, India. American Sociological Review, 318-337.

Granovetter, M. (1992). Economic institutions as social constructions: a framework for analysis. Acta Sociologica, 35(1), 3-11.

Greenwood, R., \& Suddaby, R. (2006). Institutional entrepreneurship in mature fields: The big five accounting firms. Academy of Management Journal, 49(1), 27-48.

Greve, H. R. (1996). Patterns of competition: The diffusion of a market position in radio broadcasting. Administrative Science Quarterly, 29-60.

Hannan, M. T., \& Freeman, J. (1977). The population ecology of organizations. American Journal of Sociology, 82(5), 929-964.

Ibarra, H. (1993). Personal networks of women and minorities in management: A conceptual framework. Academy of Management Review. 18(1), 56-87

Khan, A. M., \& Manopichetwattana, V. (1989). Innovative and non-innovative small firms: Types and characteristics. Management Science, 35(5), 597-606.

Levinthal, D., \& March, J. G. (1981). A model of adaptive organizational search. Journal of Economic Behavior 83 Organization, 2(4), 307-333.

Maguire, S., Hardy, C., \& Lawrence, T. B. (2004). Institutional entrepreneurship in emerging fields: HIV/AIDS treatment advocacy in Canada. Academy of Management Journal, 47(5), 657-679.

Marsh, C. P., \& Coleman, A. L. (1956). Group influences and agricultural innovations: Some tentative findings and hypotheses. American Journal of Sociology, 61(6), 588-594.

Menzel, H. (1960). Innovation, integration, and marginality: a survey of physicians. American 660 Sociological Review, 704-713.

Meyer, J. W., \& Rowan, B. (1977). Institutionalized organizations: Formal structure as myth and ceremony. American Journal of Sociology, 83(2), 340-363.

Miller, D., \& Friesen, P. H. (1982). Innovation in conservative and entrepreneurial firms: Two models of strategic momentum. Strategic Management Journal, 3(1), 1-25.

665 Nelson, A., Earle, A., Howard-Grenville, J., Haack, J., \& Young, D. (2014). Do innovation measures actually measure innovation? Obliteration, symbolic adoption, and other finicky challenges 
in tracking innovation diffusion. Research Policy, 43(6), 927-940.

O’Neill, H. M., Pouder, R. W., \& Buchholtz, A. K. (1998). Patterns in the diffusion of strategies across organizations: Insights from the innovation diffusion literature. Academy of Management Review, 23(1), 98-114.

Orlikowski, W. J. (1996). Improvising organizational transformation over time: A situated change perspective. Information Systems Research, 7(1), 63-92.

Phillips, D. J., \& Zuckerman, E. W. (2001). Middle-status conformity: Theoretical restatement and empirical demonstration in two markets. American Journal of Sociology, 107(2), 379-429.

Podolny, J. M. (1993). A status-based model of market competition. American Journal of Sociology, 98(4), 829-872.

Poole, M. S., \& Van de Ven, A. H. (1989). Using paradox to build management and organization theories. Academy of Management Review, 14(4), 562-578.

Powers, J. B., \& McDougall, P. P. (2005). University start-up formation and technology licensing with firms that go public: A resource-based view of academic entrepreneurship. Journal of Business Venturing, 20(3), 291-311.

Ravlin, E. C., \& Thomas, D. C. (2005). Status and stratification processes in organizational life. Journal of Management, 31(6), 966-987.

Ridgeway, C. L., \& Walker, H. A. (1995). Status structures. Sociological Perspectives on Social Psychology, 281-310.

Rowley, T. J. (1997). Moving beyond dyadic ties: A network theory of stakeholder influences. Academy of Management Review, 22(4), 887-910.

Rogers, E. 1995. Diffusion of innovations. New York: Free Press.

Rowan, B. (1982). Organizational structure and the institutional environment: The case of public schools. Administrative Science Quarterly, 259-279.

Simon, Herbert A. (1957). Administrative behavior (2nd ed.). New York: MacMillan.

Stewart, D. (2005). Social status in an open-source community. American Sociological Review, 70(5), 823-842.

Strang, D., \& Meyer, J. W. (1993). Institutional conditions for diffusion. Theory and Society, 22(4), 487-511.

Strang, D., \& Soule, S. A. (1998). Diffusion in organizations and social movements: From hybrid corn to poison pills. Annual Review of Sociology, 24(1), 265-290.

Suchman, M. C. (1995). Managing legitimacy: Strategic and institutional approaches. Academy of Management Review, 20(3), 571-610.

700 Terlaak, A., \& Gong, Y. (2008). Vicarious learning and inferential accuracy in adoption processes. Academy of Management Review, 33(4), 846-868.

Tolbert, P. S., \& Zucker, L. G. (1983). Institutional sources of change in the formal structure of organizations: The diffusion of civil service reform, 1880- 1935. Administrative Science Quarterly, 
22-39.

705 Trencher, G., Yarime, M., McCormick, K. B., Doll, C. N., \& Kraines, S. B. (2013). Beyond the third mission: Exploring the emerging university function of co-creation for sustainability. Science and Public Policy, 41 (2), 151-179.

Tripsas, M. (1997). Unraveling the process of creative destruction: Complementary assets and incumbent survival in the typesetter industry. Strategic Management Journal, (18), 119-142.

710 Van de Ven, A. H. (1986). Central problems in the management of innovation. Management Science, 32(5), 590-607.

Van de Ven, A. H., \& Poole, M. S. (2005). Alternative approaches for studying organizational change. Organization Studies, 26(9), 1377-1404.

White, H. C. (1981). Where do markets come from? American Journal of Sociology, 87(3), $715 \quad 517-547$.

Westphal, J. D., Gulati, R., \& Shortell, S. M. (1997). Customization or conformity? An institutional and network perspective on the content and consequences of TQM adoption. Administrative Science Quarterly, 366-394.

Westphal, J. D., \& Zajac, E. J. (1997). Defections from the inner circle: Social exchange, 720 reciprocity, and the diffusion of board independence in U.S. corporations. Administrative Science Quarterly, 161-183.

Zuckerman, E. W. (1999). The categorical imperative: Securities analysts and the illegitimacy discount. American Journal of Sociology, 104 (5), 1398-1438. 


\section{Biographies}

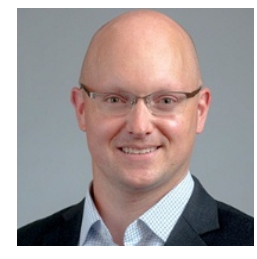

Andrew G. Earle. Andrew G. Earle received his M.B.A. and Ph.D. degrees from the University of Oregon in 2008 and 2013, respectively. Since 2013, he has been an Assistant Professor of Business Strategy and Entrepreneurship at the University of New Hampshire's Peter T. Paul College of Business and Economics. He researches how innovations move from initial invention to marketable products, services, and business models; and how this process affects and informs the strategies of participating organizations. He has published his research in leading management journals including Research Policy and Administrative Science Quarterly. He also serves as the Chair of UNH's Holloway Prize Innovation-to-Market Competition and Co-PI of UNH's NSF-sponsored "Innovation Corps" program. Dr. Earle was the Runner-up for the INFORMS Best Dissertation Award (Technology Management Section) in 2014; recipient of the Best Research Paper Award at the Sustainability, Ethics, and Entrepreneurship Conference in 2015; recipient of the Best Research Paper Award at the GRONEN Research Conference in 2016; and recipient of the IACMR Presidential Award for Responsible Research in Management in 2017. Dr. Earle was also named a Strategy Research Foundation Scholar for 20182019 . 